\title{
A GENERAL EQUILIBRIUM MODEL OF OPTIMAL ALCOHOL TAXATION IN THE CZECH REPUBLIC
}

\author{
Karel Janda, Zuzana Lajksnerová, Jakub Mikolášek*
}

\begin{abstract}
This paper provides a general equilibrium theoretical model of alcohol taxation and empirically estimates the model. For this purpose, we use a model determined by both externality corrections and fiscal considerations as the tax increase is assumed to immediately change other governmental policies such as labour taxation or medical expenditures. The results of our analysis show that under most parametric scenarios, the current Czech tax rate on beer and wine is below its optimal level and that the fiscal component has a significant impact on the optimal level of tax.
\end{abstract}

Keywords: alcohol, beer, wine, Czech Republic, elasticity, price, social costs, tax JEL Classification: H21, Q02, Q18

\section{Introduction}

This paper makes a contribution towards improved understanding of alcohol economics in the Czech Republic. It focuses on estimation of optimal beer, wine and spirit taxes, using an analogy to a method developed by Parry, et al. (2009). Our model is parametrized using values for the Czech Republic.

Our paper builds upon a line of research by Janda and his co-authors (Janda et al., 2010; Janda et al., 2010b; Janda and Mikolášek, 2011), who have dealt with Czech beer industry and provided suitable empirical estimations of elasticities of Czech alcohol demand. However, their analysis has been focused on balancing Pigouvian tax and dead-weight loss of taxation. The major contribution of our current article is the incorporation of those previous research results in a fully specified general equilibrium theoretical framework which enables in-depth economic discussion of taxation of beer, wine and spirits.

Among recent Czech and Slovak economic literature dealing with alcohol, which pays some attention mainly to wine demand and industry (Horska et al., 2016; Kucerova, 2014; Syrovatka et al., 2014; Tomsik and Prokes, 2011), two papers are particularly related

* Karel Janda, Charles University, Faculty of Social Sciences, Prague, and University of Economics,

Faculty of Finance and Accounting, Prague (janda@vse.cz);

Zuzana Lajksnerová, Charles University, Faculty of Social Sciences, Prague

(lajksnerovazu@seznam.cz);

Jakub Mikolášek, Charles University, Faculty of Social Sciences, Prague (jakub.mikolasek@gmail.com).

This project has received funding from the European Union's Horizon 2020 Research and Innovation Staff Exchange programme under the Marie Sklodowska-Curie grant agreement no. 681228. The authors further acknowledge financial support from the Czech Science Foundation (grant numbers 18-05244S and 18-26714S) and from Charles University internal support PRIMUS/17/HUM/16. Karel Janda acknowledges research support provided during his long-term visit at the Australian National University. The views expressed here are those of the authors and not necessarily those of our institutions. All remaining errors are solely our responsibility. 
to our research in their coverage of Czech alcohol demand. Slovackova et al. (2016) provide the most recent time series econometric forecast of Czech alcohol consumption and Jansky (2016) investigates the Czech excise duties (taxes) on individual types of alcoholic beverages, while building upon results of consumer demand system estimations on Czech or Slovak household budget data by Jansky (2014), Dybczak et al. (2014), Cupak et al. (2016), and Cupak et al. (2015). While Slovackova et al. (2016) deal only with time series analysis of Czech alcohol consumption without considering taxation and the general equilibrium features of our model, they are relevant to our paper in their precise coverage (beer, wine, spirits in pure alcohol content) and in their description of the empirical and institutional situation of Czech alcohol consumption. As opposed to our general equilibrium approach, Jansky (2016) relies on a partial-equilibrium framework, but his results are complementary to ours as his outputs provide valuable input parameters for the future development of our model. While our paper focuses only on alcohol, Jansky (2016) covers alcohol just as a subset of the set of all goods subjected to Czech excise duties. As opposed to our more complex representative consumer model, the much simpler model in Jansky (2016) focuses on taking own and cross-price elasticities of demand from Jansky (2014) and computing the changes in demand for fuel, alcohol and tobacco products when excise duties change exogenously. All this is done by Jansky (2016) for different income groups ordered by their total expenditure quintiles.

In the Czech wine-oriented literature, Kucerova (2014) provides a description of the Czech wine market, including the data on production, consumption and prices, while Tomsik and Prokes (2011) focus entirely on the description of the production side of Czech wine industry. On the consumption side, Horska et al. (2016) focus on investigation into consumers' preferences among different wines using an electroencephalography-based neuro-science approach. Out of this wine-oriented literature, Syrovatka et al. (2014), who provide an econometric estimation of wine consumption in the Czech Republic, are the closest to our article since they also consider cross-price elasticities of demand between wine, beer and spirits.

Existing international literature, e.g., Manning et al. (1989) and Saffer and Chaloupka (1994), usually focuses on measuring various externalities such as costs associated with drunk driving, increase in healthcare costs and the estimation of a corresponding Pigouvian tax. Kenkel (1996) concludes that alcohol taxation is not the only solution to problems connected with alcohol abuse and that stricter penalties for drunk driving together with higher public awareness of the health consequences of heavy drinking might significantly reduce social costs arising from alcohol consumption. Another study by Lyon and Schwab (1995) compares effects of alcohol taxation with respect to annual and lifetime revenues. Results of all these studies agree on the fact that past alcohol tax rates were too low.

Pogue and Sgontz (1989) as well as previous authors focus on measuring the optimal Pigouvian tax using a partial-equilibrium approach, balancing dead-weight losses of taxation due to distorted consumption choices by moderate drinkers against the benefits from reducing negative externalities arising from abusive drinking. For this purpose, 
the population is devided into several groups according to the level of their alcohol consumption/abuse. The result is either taxation near the present level or higher.

In contrast, Parry et al. (2009) consider both Pigouvian and fiscal rationales. They present an analytical framework for assessing the optimal levels and welfare effects of alcohol taxes and drunk driver penalties, accounting for both externalities and the interaction of alcohol taxes with other taxes within the broader fiscal system. In their model, the optimal alcohol tax is decomposed into four different components: a Pigouvian tax, a revenue-recycling tax, a tax-interaction effect and a productivity effect. This approach was introduced earlier in the article by Sandmo (1975), who stated that optimal tax on alcohol may differ considerably from Pigouvian tax on fiscal grounds. Empirical estimations show that fiscal considerations can significantly strengthen the case for higher alcohol taxes as the fiscal component of the optimal alcohol tax may be as large as (or even exceed) the externalitycorrecting component. Unlike in Pogue and Sgontz (1989), individual beverages have different optimal taxes because of beverage-specific fiscal components. The results of Parry et al. (2009) indicate that optimal levels of alcohol taxes in the USA are much higher than their observed level.

\section{The Model}

First, we present a model with a structure very similar to the one used in Parry et al. (2009). This static general-equilibrium model with a representative agent assumes that the agent's future costs of addiction are internalized and not undervalued and that efficiency determines optimality of policy. The fiscal system is highly simplified as government expenditures are financed only through labour taxes, excise taxes on alcohol and pecuniary penalties. ${ }^{1}$ As far as the rather complex notation in the rest of this paper is concerned, we follow the convention to use mainly lower indices, especially for values of parameters such as elasticities, etc. We use upper indices mainly for variables related to government and taxation effects.

\subsection{Preferences}

Let us assume that the agent, representing an aggregation over all households in the real economy, has a continuous, quasi-concave utility function:

$$
\begin{gathered}
U=U\left(A, D, \tau_{D} D, C, l, G, P\right), \\
H=H(A, D, \bar{D}, M) .
\end{gathered}
$$

$1 \quad$ By doing so, we silently use a simplifying assumption that both alcoholic goods and non-alcoholic goods are taxed with the same VAT rate, which is not technically correct as some consumer goods (including non-alcoholic beverages) are subject to a lower tier of tax. The lower-bracket goods, however, account for only a small fraction of total tax revenue. In order to account for the lower VAT brackets, we would need to include alcoholic/non-alcoholic goods elasticity of substitution for each VAT bracket, which would make our model much more complex. 
In (1) all the variables are expressed on a per capita basis and the bar accent in (2) depicts a variable exogenous to our agent. $U$ is a function increasing in all arguments except $\tau_{D} D$ and $H$. The agent can choose arbitrarily the consumed volume of alcohol $A$ and nonalcoholic goods $C$, number of driving trips under the influence of alcohol $D$ and leisure time $l . \tau_{D}$ denotes non-pecuniary penalties (e.g., license suspensions, jail) per drunk driver trip. $G^{P}$ is government spending on public goods and $H$ health risks, further explained in the next paragraph.

The consumed volume of alcohol $A$ and the number of driving trips under the influence of alcohol $D$ are considered to be complements, in particular emphasizing that driving under the influence of alcohol increases with an increase in alcohol consumption. Since the focus of this paper is on alcohol, we single out driving trips under the influence of alcohol out of all driving trips as one of the arguments of the utility function $U$ under the influence of. All other driving trips are included in the general residual category of non-alcoholic goods $C$.

This modelling choice definitely does not mean that drivers would generally enjoy driving more while drunk. For sober driving, it is included in $C$, with $\partial U / \partial C>0$, for drunk driving with $\partial U / \partial D>0$, we just model the empirical fact that people sometimes voluntarily drive under the influence of alcohol. We fully agree with Sloan and Eldred (2015, p.242) that "driving while intoxicated is unlikely to yield utility in its own right". In the framework of a rational utility-maximizing decision-maker used in this article, trips under the influence of alcohol enter into the utility function when the decision-maker concludes that all his costs of drunk driving are lower than the benefits he obtains from the intended driving trip. In this article, having drunk driving in the utility function represents a reduced form of modelling the empirical fact that some people sometime drive drunk. For a detailed discussion of preferences of drinker-drivers and modelling the decisions to drive under the influence of alcohol, we refer the reader to Sloan and Eldred (2015).

Health risks $H$ comprise risks of becoming ill, injured, disabled or killed due to heavy drinking or alcohol-involving traffic incidents. These risks are defined in (2) by the continuous, quasi-concave function, increasing with the agent's own alcohol consumption, drunk driving, drunk driving committed by others $\bar{D}$ and decreasing with the agent's consumption of medical services $M$, as this mitigates health risks and improves the chance of recovery.

\subsection{Production}

Let us assume there are no pure profits on the production side of the economy because alcohol, general goods, medical and car services are produced by competitive firms with constant returns to scale. Therefore, producer prices are fixed and firms pay a gross wage of $w$ that is equal to the value of a marginal product of labour. Effective labour supply is defined as $W=w L$, where $L$ is labour supply (time at work). Changes in $H$ are assumed to have a negative impact on $W(\partial W / \partial H<0)$.

The government pays for a fraction $s$ of medical care costs, while the rest $1-s$ is paid for by private insurance and car insurance companies that cover their costs through charging a variable payment amounting to the fraction $v_{M}$ of medical expenses charged 
by insurance companies or $v_{D}$ per drunk driver trip charged by car/insurance companies $\left(v_{D}<c_{D}\right.$ where $c_{D}$ is the expected costs of car repair) and also a lump-sum premium to households of $K_{M}$ (respectively $K_{D}$ ). Insurance companies' profits are zero in the equilibrium because $v_{M}$ and $v_{D}$ adjust, $K_{M}$ and $K_{D}$ are given.

\subsection{Government}

The government faces the following budget constraint:

$$
G^{P}+G^{t}+s M=t_{L} W+t_{A} A+\left(t_{D}-r\right) D .
$$

The left-hand side of Equation (3) describes three kinds of government spending:

$G^{P}$ spending on public goods,

$G^{t}$ lump-sum transfer spending,

$s M$ government medical expenditures.

These expenses are financed by revenues, which are described on the right-hand side:

$t_{L}$ proportional tax on labour income,

$t_{A}$ excise tax on alcohol,

$t_{D} \quad$ expected fine per drunk driver trip.

$r=r\left(v_{D}, t_{D}\right)$ denotes resource costs expended by the government in order to enforce drunkdriver penalties and it is increasing with both $v_{D}$ and $t_{D}$.

\subsection{Agent optimization}

Agents face the following budget and time constraints:

$$
\begin{gathered}
\left(1-t_{L}\right) W+G^{T}=\left(p_{A}+t_{A}\right) A+C+K_{M}+v_{M} M+K_{D}+v_{D} D+t_{D} D, \\
T(H)=L+l .
\end{gathered}
$$

In the first equation, the net tax labour income and the government transfer spending cover the expenditures on alcohol ( $p_{A}$ is the producer price of alcohol), general consumption, lump-sum and variable costs paid to medical and car insurance companies and drunk driver fines. $T$ is available time divided between leisure and labour, a function decreasing with health risks $H$.

The consumer's maximization problem yields the first-order conditions:

$$
\begin{array}{cc}
\frac{U_{A}}{\lambda}=p_{A}+t_{A}+m p c H_{A} & \frac{U_{D}}{\lambda}=v_{D}+t_{D}+\tau_{D}+m p c H_{D} \\
-m p c H_{M}=v_{M} & \frac{U_{l}}{\lambda}=\left(1-t_{L}\right) w .
\end{array}
$$

In (5) we have normalized $-\frac{U_{\tau_{D} D}}{\lambda}=1, \lambda$ is the marginal utility of income and $m p c=-\left(U_{H} / \lambda+\left(1-t_{L}\right)\left(w T_{H}+W_{H}\right)\right)$ denotes the marginal private costs of health risks, which consist of direct disutility from suffering $-U_{H} / \lambda$, the value of lost time from 
incapacitation or premature mortality $-\left(1-t_{L}\right) w T_{H}$ and foregone private earnings from lower workplace productivity $-\left(1-t_{L}\right) W_{H}$.

It is seen from (5) that agents increase their alcohol consumption up to a point where the marginal benefit received from the last unit of drink is equal to the tax-inclusive alcohol price and the own-health costs. Similarly, driving under the influence of alcohol is committed until the marginal benefits from drunk driving equals the expected out-ofpocket expenses for car crashes, monetized government penalties, and own health risks. Individuals also equate the marginal private benefits from medical care with the variable costs and the marginal benefits from leisure with the net wages.

\subsection{Marginal welfare effect from an increase in tax on alcohol}

Totally differentiating the indirect utility function (see the Appendix for derivation and definition of elasticities), we obtain the marginal welfare effect from an increase in $t_{A}$, accounting for any changes in $t_{L}, G^{T}$ and $G^{P}$ to maintain government budget balance.

$$
\begin{gathered}
\left(E^{A}-t^{A}\right)\left(\frac{-\partial A}{\partial t_{A}}\right)+t_{L}\left(\frac{\partial W}{\partial t_{A}}\right)+M E G_{G^{P}}\left(\frac{\partial G^{P}}{\partial t_{A}}\right), \\
E^{A}=\left(1-v_{M}\right) M_{A}+E^{D} D \eta_{D A} / A \eta_{A A}, \\
E^{D}=m p c H_{\bar{D}}+c_{D}-v_{D}+\left(1-v_{M}\right)\left(M_{D}+M_{\bar{D}}\right)+r-t_{D} .
\end{gathered}
$$

In these expressions:

$\eta_{A A}<0$ elasticity of alcohol consumption with respect to the price of alcohol, $\eta_{D A}<0$ elasticity of alcohol drunk driving with respect to the price of alcohol,

$M E G_{G^{P}}=U_{G^{P}} / \lambda-1$ denotes marginal efficiency gain/loss from spending on public goods and $E^{A}$ stands for the marginal external costs of alcohol consumption. Finally, $E^{D}$, denoting the external costs per drunk driver trip, is independent of the non-pecuniary penalty $\tau_{D}$, which implies that the optimal level of alcohol taxes will be independent of the level of non-pecuniary penalties as well.

The change in effective labour supply in (6) is defined as

$$
\frac{\partial W}{\partial t_{A}}=\frac{\partial W}{\partial H} \frac{\partial H}{\partial t_{A}}+\frac{w \partial L}{\partial t_{A}}+w\left(\frac{\partial L}{\partial t_{L}} \frac{\partial t_{L}}{\partial t_{A}}+\frac{\partial L}{\partial G^{T}} \frac{\partial G^{T}}{\partial t_{A}}\right) .
$$

The change in effective labour supply has three components: the increase in productivity due to the effect of lower alcohol consumption on reducing illness or road injuries, the labour supply effect of raising the price of alcohol relative to leisure and the effect of revenue recycling (leisure is a normal good, so if we use revenues to decrease $t_{L}$, labour supply increases and it decreases if we use them to increase $G^{T}$ ).

\subsection{Optimal tax with revenue neutrality}

Through the optimization, it is assumed that the government's goal is to maximize the utility of an agent by finding the optimal level of $t_{a}$, given the level of $G^{T}$ and $G^{P}$, and keeping 
the budget balanced when using all the revenues to reduce the labour tax $t_{l}$. From the first equation in (6) and (7), we calculate the optimal alcohol tax (see derivation in the Appendix):

$$
t_{A}^{*}=P V^{A}+R R^{A}-T I^{A}+P R^{A},
$$

where:

$$
\begin{gathered}
P V^{A}=E^{A} ; R R^{A}=M E G_{t_{L}}\left\{\frac{p_{A}+t_{A}}{-\eta_{L L}}-t_{A}+g^{A}\right\} \\
T I^{A}=\frac{\left(1+M E G_{t_{L}}\right) t_{L}\left(p_{A}+t_{A}\right)\left(\eta_{A l}^{C}+\eta_{L l}\right)}{\left(1-t_{L}\right)\left(-\eta_{A A}\right)} ; P R^{A}=\left(1+M E G_{t_{L}}\right) t_{L}\left(-W_{H} H_{A}\right), \\
M E G_{t_{L}}=\frac{-t_{L} \frac{\partial L}{\partial t_{L}}}{L+t_{L} \frac{\partial L}{\partial t_{L}}}=\frac{\frac{t_{L}}{1-t_{L}} \eta_{L L}}{1-\frac{t_{L}}{1-t_{L}} \eta_{L L}}, \\
g^{A}=s M_{A}+\left\{s\left(M_{D}+M_{\bar{D}}\right)+\left(r-t_{D}\right)\right\} D \eta_{L L} / A \eta_{A A}
\end{gathered}
$$

where

$\eta_{A l}$ elasticity of demand for alcohol with respect to the price of leisure,

$\eta_{L L}$ labour supply elasticity. $\eta_{L L}>0$

$\eta_{L I}$ income elasticity of labour supply. $\eta_{L L}<0$

$c$ denotes a compensated elasticity (all elasticities are defined in the Appendix).

In Equation (9), $M E G_{t_{L}}>0$ is the efficiency gain from using a unit of revenue to cut the labour tax. It can be seen from (8) that the optimal alcohol tax consists of four components: the marginal external costs of alcohol consumption $E^{A}$ and three other components that arise from various fiscal interactions.

$P V^{A}$ (or $E^{A}$ ) is the Pigouvian tax, the marginal external costs of alcohol (see (6) for the detailed formula). These costs are divided into two parts. The first is the fraction of medical costs due to the health risks from alcohol consumption paid by third parties (government and insurance companies). The second component accounts for drunk driver trip costs.

The first extra component is the revenue-recycling tax $\left(R R^{A}\right)$, which captures changes in both tax revenues and alcohol-related public expenditure induced by alcohol tax. It is equal to $M E G_{t_{l}}$ times marginal revenue to the government from raising the alcohol tax, including indirect savings in government medical and resource expenditures $g^{A}$. Regarding the role of price elasticity of alcohol demand: the lower it is, the greater the tax revenue from alcohol taxation, as well as the revenue-recycling component.

The second extra component $T I^{A}$ is the tax-interaction effect which arises from the change in labour supply as the alcohol price rises relative to the price of leisure, multiplied by $1+M E G_{t_{L}}$ to account for the change in labour tax revenue. To maintain the government revenue balanced, $t_{L}$ must be changed. When alcohol and leisure are complements $\left(\eta_{A l}{ }^{C}<0\right)$, the alcohol tax increases the labour supply and the tax-interaction 
effect is positive. It also includes the income effect from higher alcohol prices, which reduces labour supply because leisure is a normal good $\left(\eta_{L I}<0\right)$. If alcohol and leisure were substitutes $\left(\eta_{A l}{ }^{C}>0\right)$, the alcohol tax would decrease both labour supply and labour tax revenue, which implies the negativity of the tax-interaction effect. In reality, the relationship between alcohol and leisure may not be straightforward. There is a simple rationale behind the assumption of complementarity - alcohol consumption by definition takes time, especially if consumed in a gastronomic facility. On the other hand, alcohol consumption, especially of a lower level, may readily be complementary to time spent working (and thus a substitute to leisure), either as a short-term relief from work-induced stress, or as a result of socializing with colleagues. As mentioned by the Institute for Fiscal Studies (2009), the former effect may be underreported since heavy drinkers generally tend to underreport their consumption in official surveys and it is therefore possible that some countries could report alcohol and leisure as mild substitutes.

Finally, as the third component, there is the productivity effect $\left(P R^{A}\right)$, expressed in per unit reduction in alcohol consumption. Taxing alcohol reduces drinking and also drunk driving, resulting in better health of individuals and positive effect on effective labour supply. It equals the health-induced increase in productivity per unit reduction in alcohol $-W_{H} H_{A}=(\partial W / \partial H)(d H / d A)$ times the labour tax $t_{L}$, times $1+M E G_{t_{L}}$ to account for the change in labour tax revenue.

\subsection{Taxation of individual beverages}

Now, let us assume that:

$$
\begin{gathered}
A=A_{B E}+A_{W I}+A_{S P}, \\
E^{A i}=E^{A} ; H^{A i}=H^{A},
\end{gathered}
$$

where the alcohol consumption $A$ is a sum of individual beverages consumed: beer $(B E)$, wine $(W I)$ and spirits $(S P)$. The second equation indicates that marginal external costs $E^{A i}$ and productivity effects $H^{A i}$ per unit of alcohol are the same across these beverages.

We calculate optimal taxes on these individual beverages as:

$$
\hat{t}_{i}=t_{i}^{*}-\sum_{k \neq i}\left(t_{k}^{*}-\hat{t}_{k}\right)\left(\frac{\eta_{k i} A_{k}}{\eta_{i i} A_{i}}\right),
$$

where $i, k=B E, W I, S P$ and $\eta_{i i}, \eta_{k l}$ denote own and cross-price beverage elasticities. $t_{i}^{*}$ is the optimal tax in the absence of cross-price effects among beverages and it is analogous to that in (8). Therefore, the more elastic and complementary to leisure a beverage is, the higher an optimal tax on that beverage is likely to be.

\subsection{Other considerations}

Although the above model could already be considered quite complex, it does not and perhaps even could not capture all the effects that could potentially interact in the system. Let us mention at least one of these omissions that could be considered important as well as controversial at the same time. The fact that drinking could cause higher death rates (either by sudden deaths under the influence of alcohol by one of the actors, or after a long-term 
alcohol-related health condition) also means that such deaths generally occur at a lower age than if the individual were to abstain. This implies that there could be potential government savings (on retirement pensions and/or costs of future medical treatment unrelated to alcohol) in case a person died earlier because of his/her drinking habits. In fact, a study dealing with a similar matter for the Czech Republic in detail (Hait, 2012) concludes that because of these effects, smoking really seems even to be beneficial for the Czech state budget (at the expense of the individuals affected). As analysing this problem would bring another level of complexity to the model, but result in only a redistribution of the costs and benefits between individuals and the state budget, we treat this omission as justifiable.

\section{Parametrization of the Model}

Let us now describe the parameter values of our model. If not stated otherwise, all values were estimated for a 2012 baseline. For important parameters that are calculated or estimated with some degree of uncertainty, we usually consider three different values to obtain the mid, low (conservative) and high (non-conservative) estimates. We allow $\mathrm{a} \pm 30 \%$ variation to find the lower and upper limit.

\subsection{Alcohol market and labour tax}

To calculate the total consumption of pure alcohol (or ethanol) in the Czech Republic, we first need to find out how many litres of pure alcohol were contained in the amount of beer, wine and spirits consumed (computed in Table 1).

Table 1 | Per Capita Amount of Pure Alcohol Consumed

\begin{tabular}{|l|c|c|c|c|}
\hline Beverage & $\begin{array}{c}\text { Per-capita } \\
\text { consumption }\end{array}$ & $\begin{array}{c}\text { Alcohol } \\
\text { content }\end{array}$ & $\begin{array}{c}\text { Per-capita consumption } \\
\text { of pure alcohol }\end{array}$ & $\begin{array}{c}\text { Share in total pure } \\
\text { alcohol consumed }\end{array}$ \\
\hline Beer & $148.6 \mathrm{I} /$ year & $4.5 \%$ & $6.687 \mathrm{I} /$ year & $57.0 \%$ \\
\hline Wine & $19.8 \mathrm{I} /$ year & $12.0 \%$ & $2.376 \mathrm{I} /$ year & $20.2 \%$ \\
\hline Spirits & $6.7 \mathrm{I} /$ year & $40.0 \%$ & $2.680 \mathrm{I} /$ year & $22.8 \%$ \\
\hline
\end{tabular}

Source: Own calculation based on Czech Statistical Office data

The initial alcohol consumption $A$ is thus 11.7431 of pure ethanol per capita per year, which means $123,365,4411$ of pure alcohol in total at the 2012 population level of the Czech Republic of 10,505,445 inhabitants (CSO, 2012) $)^{2}$.

$2 \quad$ The figures by the Czech Statistical Office (C) are constructed using a balance method (taking import and export of alcohol into account), but are likely to fail in capturing the tourism effect. The incoming tourism in 2012 accounted for 8.9 million visitors (excluding overnight stays and transfers) whereas the number of foreign visits by the Czechs is estimated to only 5.4 million. Taking into account that alcohol is generally cheaper in the Czech Republic than in most of the tourists' countries of origin as well as in travel destinations visited by Czechs, it is legitimate to assume that foreign tourists inside the Czech Republic consume more alcohol (in total terms) that Czechs consume abroad. The per capita figures by the CSO could therefore be overestimated. 
The average price of one litre of beer, wine and spirits, taken from Czech Household Budget Survey data from 2012 reached 24.30 CZK, 66.18 CZK and 246.21 CZK respectively. For the purpose of our analysis, we are not interested in the price of a litre of the particular drink, but rather the price of such an amount of the beverage that contains one litre of pure ethanol (22.221 of $4.5 \%$ beer, 8.331 of $12 \%$ wine and 2.501 of $40 \%$ spirit). These imply prices $p_{a}$ of $539.95 \mathrm{CZK}$ for beer, $551.28 \mathrm{CZK}$ for wine and $615.53 \mathrm{CZK}$ for spirits, where all the prices are per litre of pure alcohol.

The current alcohol tax rate $t_{a}$ is calculated as a sum of excise tax and VAT, which is the same for all the three beverage types: $21 \%$, the basic rate (the VAT for 1 litre of pure alcohol in beer, wine and spirits is therefore $113.39 \mathrm{CZK}, 115.77 \mathrm{CZK}$ and 129.26 CZK). On the other hand, excise tax differs for every one of them. For spirits it is $285 \mathrm{CZK} / 1$, while for still wines, excise tax does not apply at all. Calculation of excise tax on beer is a little more complicated - it depends on both the brewery size and the content of original wort extract (details can be found in Table 2).

Table 2 | Excise Tax on Beer

\begin{tabular}{|c|c|}
\hline $\begin{array}{c}\text { Brewery size } \\
\text { (hl of beer produced) }\end{array}$ & $\begin{array}{c}\text { Tax rate for } \mathbf{1 \%} \text { of original wort } \\
\text { extract in } \mathbf{1} \text { litre }\end{array}$ \\
\hline$<10,000$ & $16.0 \mathrm{CZK}$ \\
\hline $10,000-50,000$ & $19.2 \mathrm{CZK}$ \\
\hline $50,000-100,000$ & $22.4 \mathrm{CZK}$ \\
\hline $100,000-150,000$ & $25.6 \mathrm{CZK}$ \\
\hline $150,000-200,000$ & $28.8 \mathrm{CZK}$ \\
\hline$>200,000$ & $32.0 \mathrm{CZK}$ \\
\hline
\end{tabular}

Source: Zákon o spotřebních daních. 353/2003 Sb.

Calculating with the standardized rate of $0.31 / 1$ (over $90 \%$ of beer is produced in breweries with a production over $200,000 \mathrm{hl}$ ) and the average 11 degrees Plato beer, we get a beer excise tax of $3.41 \mathrm{CZK} / 1$ of beer or $75.02 \mathrm{CZK} /$ amount of beer containing 1 litre of pure alcohol.

Altogether, the current alcohol tax rate $t_{a}$ per litre of pure alcohol is estimated to be 188.41 CZK for beer, 115.77 CZK for wine and 414.26 CZK for spirits.

In 2011, the implicit tax rate on labour was 39\% in the Czech Republic (Eurostat, 2013). Given the fact that the real GDP was approximately the same in 2012 and the government did not implement any new policies concerning income tax, $t_{L}=0.39$ remains valid for 2012 as well and is therefore applied throughout this paper. 


\subsection{Drunk driving}

In 2012, the Police of the Czech Republic recorded a total of 4,974 traffic accidents caused by drunk driving. In these accidents, 45 persons were killed and 2,770 were injured. Alcohol in drivers' blood was also detected during 11,037 roadside checks. Altogether, there were 16,011 drunk driver trips registered in 2012. Nevertheless, this value represents only a small fraction of the actual number.

According to data of the Czech Ministry of Transport, drivers with a blood alcohol level higher than the allowed amount ${ }^{3}$ account for approximately $2 \%$ of total kilometres travelled within the EU countries. Assuming 10,000 kilometres travelled per year per driver, an average trip length of 20 kilometres and the proportion of drivers in the population of $64.62 \%$ gives initial drunk driver trips $D$ equal to $67,886,186$ with the proportion of registered drunk driving lower than $0.024 \%$. The expected fine per drunk driver trip $t_{D}-5.9 \mathrm{CZK}$ is calculated as the maximum penalty rate that can be charged in the Czech Republic for driving under the influence of alcohol $(25,000 \mathrm{CZK})$ multiplied by the share of registered drunk driving in the total estimated drunk driving.

\subsection{External costs}

In order to separate the Pigouvian part of our model properly, we need to split the costs into a part internalized by the drinker and a part that represents damage caused to others. Unfortunately, Czech police statistics do not provide the split between internal and external consequences of car incidents. In order to approximate this, we refer to Levitt and Porter's (2001) estimate that only $16.8 \%$ of injuries in alcohol-involved crashes are external. Applying the same ratio to alcohol-related incidents registered in 2012 in the Czech Republic results in eight fatalities and 471 injuries being external. For fatalities, the marginal private costs $m p c$ correspond to estimates of the value of life. The Czech Supreme Court assumes a value of life of 10,051,200 CZK per person; thus, 80,409,760 CZK is the estimated value of eight lives.

Estimating compensation for non-fatal injuries is a more complicated task. Under the Czech law, every injury or social impairment caused by a traffic accident has a different value in points, which then define the compensation. The value of one point is $120 \mathrm{CZK}$. Averaging all these compensations gives a mean value of 72,000 CZK (meaning 33,912,000 CZK for 471 injuries), which we set as the marginal private costs $m p c$ of non-fatal external injuries. Aggregating over the value of fatal and non-fatal injuries and dividing by alcohol consumption gives a value for $m p c H_{\bar{D}} D / A=0.927 \mathrm{CZK}$ per litre of alcohol.

Based on data from the Ministry of Finance, we estimate the total costs of car repairs to be 500 million CZK. In the Czech Republic, car accident costs are almost entirely covered by mandatory car insurance. Average individual financial participation reaches only $9 \%$ of the damage in an accident. Dividing by alcohol consumption results in net property damages of $\left(c_{D}-v_{D}\right) D / A=3.68 \mathrm{CZK}$ per litre of pure alcohol, where $c_{D} D$ denotes total property damages from drunk driving and $v_{D} D$ provides an adjustment for drivers' private contribution through their insurance.

3 The allowed amount varies across EU countries. For the Czech Republic, it is zero. 
Adjusted European average data from Anderson and Baumberg (2006) have been used for the calculation of government resource costs from implementing drunk driver penalties (including law, police and jailing costs). Values for the Czech Republic were obtained by multiplying European data by the ratio of Czech inhabitants to the EU (2.09\%), the ratio between average Czech and EU alcohol consumption (116\%) the 2006 mid-year EUR/CZK exchange rate (27.495, source: Czech National Bank) and a conversion factor - the ratio of $\mathrm{CZ} / \mathrm{EU}$ labour productivity (49.6\%, source: Eurostat) for the productivity parameters and purchasing price parity ratio (79.3\%, source: Eurostat). The estimated legal costs of alcohol-related crime are 5,900 million CZK. Alcohol-related car incidents are closely linked to alcohol-related costs of crime. Again referring to Anderson and Baumberg (2006), we assume that alcohol-related car incidents accounted for $88 \%$ of the previously mentioned amount, thus 5,192 million CZK and $r / A=42.09 \mathrm{CZK}$ per litre of pure alcohol.

Using again the European data, we can estimate the medical expenditures connected to treatment of alcohol-related health problems to be 6.7 billion CZK. This estimate includes costs of treatment of diseases caused by alcohol consumption, own drunk driving and drunk driving of others. Unlike the US healthcare system, Czechs have most of the medical services paid by the government through their taxes. The variable payment $v_{M}$ (which consists mainly of costs of medicaments) must therefore be lower than in Parry et al. (2009) and we assume it to be 0.1 .

All the above mentioned values give together $E^{A}=106.93 \mathrm{CZK}$ per litre of pure alcohol. This value is the same for all the three beverages.

\subsection{Elasticities and marginal efficiency gain}

Elasticities used to derive the optimal tax level are presented in Table 3.

Table 3 | Elasticities Applied

\begin{tabular}{|l|c|c|c|c|}
\hline \multicolumn{1}{|c|}{ Parameter } & Notation & Low & Mid & High \\
\hline $\begin{array}{l}\text { Drinking with respect to leisure } \\
\text { (compensated) }\end{array}$ & $\eta_{A l}^{C}$ & 0.10 & -0.05 & -0.20 \\
\hline $\begin{array}{l}\text { Labour supply with respect to } \\
\text { income }\end{array}$ & $\eta_{L I}$ & -0.10 & -0.10 & -0.10 \\
\hline $\begin{array}{l}\text { Labour supply with respect to } \\
\text { wage rate }\end{array}$ & $\eta_{L L}$ & 0.15 & 0.15 & 0.15 \\
\hline $\begin{array}{l}\text { Drinking with respect to alcohol } \\
\text { price - beer }\end{array}$ & $\eta_{b b}$ & -0.97 & -0.97 & -0.97 \\
\hline $\begin{array}{l}\text { Drinking with respect to alcohol } \\
\text { price - wine }\end{array}$ & $\eta_{w w}$ & -1.09 & -1.09 & -1.09 \\
\hline $\begin{array}{l}\text { Drinking with respect to alcohol } \\
\text { price - spirits }\end{array}$ & $\eta_{s s}$ & -1.21 & -1.21 & -1.21 \\
\hline
\end{tabular}

Source: Parry et al. (2009), Janda et al. (2010) 
The elasticity of drinking with respect to leisure $\eta_{A l}^{C}$ was drawn from Parry et al. (2009), who indicate an interval between 0.1 and -0.2 , and -0.05 is used as the mid value. In this case, using three different values is really appropriate because of limited evidence on this parameter, which is more suggestive than definitive.

Own-price alcohol elasticities have been estimated in numerous studies - among others, let us name Hogarty and Elzinga (1972), Gallet (2007), Fogarty (2010) and among the most recent ones Nelson (2014), Srivastava et al. (2014) and Meng et al. (2014). Significantly fewer authors have also focused on cross-price elasticities of alcoholic beverages. In this paper, we will use elasticities calculated by Janda et al. (2010), based on the data from the Czech Household Budget Survey, presented in Table 4, which seem to be the most suitable for our purposes. They also focus on both own and cross-price elasticities. Therefore, we assume the own-price elasticities $\eta_{A A}$ of beer, wine and spirits to be $-0.9715,-1.0880$ and -1.2104 respectively.

We assume $\eta_{D A}=\eta_{A A}$ based on estimated responses of drunk driving and highway fatalities to alcohol prices.

Table 4 | Alcohol Price Elasticities

\begin{tabular}{|l|c|c|c|}
\hline & Beer & Wine & Spirits \\
\hline Beer & $-\mathbf{0 . 9 7 1 5}$ & -0.0681 & 0.0933 \\
\hline Wine & -0.1143 & $-\mathbf{1 . 0 8 8 0}$ & 0.0491 \\
\hline Spirits & 0.2047 & 0.2302 & $\mathbf{- 1 . 2 1 0 4}$ \\
\hline
\end{tabular}

Source: Janda et al. (2010)

There is a vast amount of literature estimating labour supply elasticity. The majority agree on the fact that it is inelastic. For the purpose of this paper, we use the value of $\eta_{L L}=0.15$ analogous to Parry et al. (2009), which is averaged over all male and female workers and hours worked. The latter produces an outcome of $M E G_{t_{L}}$ of approximately 0.106 .

Finally, for labour supply elasticity with respect to income $\eta_{L I}$, we use the value of $\eta_{L I}=-0.1$, which is also applied in both Saar (2011) and Parry et al. (2009).

\subsection{Productivity effect}

According to the estimates by Anderson and Baumberg (2006) from the Institute of Alcohol Studies, we could estimate total workplace productivity costs due to the lower state of health of alcohol abusers and those that arise from increased absence at work while influenced by alcohol consumption to be 4.7 billion CZK. For the revenue-neutral alcohol tax this implies productivity costs $W_{H} / A$ of $26.7 \mathrm{CZK}-49.50 \mathrm{CZK}$ per litre of pure alcohol with a mean value of $38.1 \mathrm{CZK}$ per litre of pure alcohol. 


\section{Results - Optimal Taxation for the Czech Republic}

Results of the simulation are presented in Tables 5, 6 and 7 .

Table 5 | Optimal Tax on Beer (CZK per litre of pure alcohol)

\begin{tabular}{|l|r|r|r|}
\hline Components of alcohol tax & \multicolumn{1}{|c|}{ Low } & \multicolumn{1}{c|}{ Mid } & \multicolumn{1}{c|}{ High } \\
\hline Pigouvian & 106.93 & 106.93 & 106.93 \\
\hline Revenue-recycling & 59.54 & 59.54 & 59.54 \\
\hline Tax-interaction & 0 & 106.03 & 159.05 \\
\hline Productivity & 11.52 & 16.44 & 21.36 \\
\hline Total & $\mathbf{1 7 7 . 9 9}$ & $\mathbf{2 8 8 . 9 4}$ & $\mathbf{3 4 6 . 8 8}$ \\
\hline Current & - & 188.41 & - \\
\hline
\end{tabular}

Source: Own calculation.

As shown, the optimal tax rate for beer ranges from 177.99 CZK to 348.66 CZK per litre of pure alcohol with a mid estimate of $288.94 \mathrm{CZK}$. The low, mid and high estimates of optimal tax (sum of VAT and excise tax) on 0.51 of beer are therefore $4 \mathrm{CZK}, 6.5 \mathrm{CZK}$ and $7.8 \mathrm{CZK}$. While the low estimate is slightly below the current tax rate of $4.2 \mathrm{CZK}$ per 0.51 of beer, both the mid and high estimates exceed the current tax level.

The high estimate represents almost $200 \%$ of the low estimate, which seems to be a reasonable difference. Individual estimates differ in the tax-interaction effect and the productivity effect. The variability is caused mainly by differences in elasticities of drinking with respect to leisure (from 0.1 to -0.2 ) applied to derive the low, mid and high estimates.

The most volatile component of the optimal tax is the tax-interaction effect. On the one hand, it disappears completely under the low-case assumptions, because under the given parameter values the substitution effect between alcohol and leisure, which decreases labour supply, is offset by the income effect from the higher alcohol price that in turn increases labour supply. On the other hand, it represents almost the same proportion of the optimal tax as the entire Pigouvian tax in the mid estimate. Finally, the tax-interaction effect under the high estimate is so high that it represents over $45 \%$ of the total optimal tax rate.

Table 6 | Optimal Tax on Wine (CZK per litre of pure alcohol)

\begin{tabular}{|l|c|c|c|}
\hline Components of alcohol tax & Low & Mid & High \\
\hline Pigouvian & 106.93 & 106.93 & 106.93 \\
\hline Revenue-recycling & 52.75 & 52.75 & 52.75 \\
\hline Tax-interaction & 0 & 86.71 & 130.07 \\
\hline Productivity & 11.52 & 16.44 & 21.36 \\
\hline Total & 171.20 & $\mathbf{2 6 2 . 8 3}$ & $\mathbf{3 1 1 . 1 1}$ \\
\hline Current & - & 115.77 & - \\
\hline
\end{tabular}

Source: Own calculation. 
Similarly to the results from the USA presented in Parry et al. (2009), the fiscal component (which we define by the revenue-recycling component net of the tax-interaction effect) of the total tax rate under the mid and high estimates exceeds the Pigouvian tax. This fact highlights the need for both fiscal and externality consideration. Productivity effects play only a marginal role in the level of beer tax.

In order to obtain the optimal beer tax, we had to calculate the optimal tax on wine and spirits as well. Like the current tax, the calculated optimal wine taxation is the lowest of all the three beverages. The optimal tax on wine was estimated to be $171.20 \mathrm{CZK}-311.11 \mathrm{CZK}$ per litre of pure alcohol with the mid value of $262.83 \mathrm{CZK}$. After the recalculation we get 20.54 CZK - 37.35 CZK per litre of wine, which is way above the current level of $13.88 \mathrm{CZK}$.

Table 7 | Optimal Tax on Spirits (CZK per litre of pure alcohol)

\begin{tabular}{|l|c|c|c|}
\hline Components of alcohol tax & \multicolumn{1}{|c|}{ Low } & Mid & High \\
\hline Pigouvian & 106.93 & 106.93 & 106.93 \\
\hline Revenue-recycling & 46.30 & 46.30 & 46.30 \\
\hline Tax-interaction & 0 & 120.33 & 180.49 \\
\hline Productivity & 11.52 & 16.44 & 21.36 \\
\hline Total & $\mathbf{1 6 4 . 7 5}$ & $\mathbf{2 9 0 . 0 0}$ & $\mathbf{3 5 5 . 0 8}$ \\
\hline Current & - & 414.26 & - \\
\hline
\end{tabular}

Source: Own calculation.

The current level of Czech tax on spirits is significantly higher than those on wine and beer for a number of fiscal, social and public policy reasons. While the general EU principle of free movement of goods supports the same taxation of alcoholic beverages so that lower or higher taxation on particular beverages does not violate fair competition, the EU Council Directive 92/83/EEC, which has in force since 1992 (as of February 2018), explicitly allows different levels of excise duties among beer, wine and spirits. The original European Commission intention dating back to 1989 was to have the same excise duties for all alcoholic beverages based on pure alcohol content; however, member states with low taxation on wine or with high taxation on beer did not agree with this (Siroky, 2016). Different taxation on beer, wine and spirits is driven mainly by efforts of particular countries or groups of countries to have lower taxation on their "national" alcoholic beverages (for example, wine in southern countries, whisky in Ireland and the United Kingdom, beer in Central European countries). This in turn allows wine production/distribution lobbies in countries such as the Czech Republic to keep low taxation on wine even in countries with different "national" beverages. The results of our analysis show that although the optimal level of tax rate on spirits is still the highest of all the beverages presented, it is way below its current level for all low, mid and high estimates. The value of the mid estimated tax on 1 litre of $40 \%$ spirit of $116 \mathrm{CZK}$ represents only about $70 \%$ of the current tax. 
Some of the exogenous variables, which were taken from other studies, play a significant role in our model. As it is not easy to confirm the validity of these assumptions for the case of the Czech Republic, it is worth assessing the impact that a change in the most important ones would have on the overall result of optimal tax calculation in our model. Given the construction of our model (see Section 3), we assessed the sensitivity of our results based on the four key external elasticity variables. On top of that, we also included labour tax because it can be easily adjusted by the government. The sensitivity analysis was made to give the reader an impression of the individual attributes' strength in the model and it was made just for the mid scenario for the sake of simplicity of presentation. By definition, the sensitivity for the low and high scenarios would be different given the non-linear relationship, especially for the tax interaction effect. The impact of magnifying the key factors by $1 \mathrm{pp}$ (e.g., increasing the absolute value of particular elasticity variable by $1 \mathrm{pp}$ while all other variables are held fixed) is summarized in Table 8 .

Table 8 | Sensitivity analysis

\begin{tabular}{|l|c|c|c|c|}
\hline \multirow{2}{*}{ Increase (in absolute terms) in: } & \multirow{2}{*}{ Notation } & \multicolumn{2}{|c|}{ Change in optimal tax value (\%) } \\
\cline { 3 - 5 } & & Beer & Wine & Spirits \\
\hline $\begin{array}{l}\text { Corresponding beverage's own-price } \\
\text { elasticity by -1pp }\end{array}$ & $\eta_{i i}$ & -0.582 & -0.487 & -0.493 \\
\hline $\begin{array}{l}\text { Elasticity of demand for alcohol with respect } \\
\text { to leisure by -1pp }\end{array}$ & $\eta_{A l}^{C}$ & 1.835 & 1.649 & 2.075 \\
\hline Income elasticity of labour supply by -1pp & $\eta_{L I}$ & 1.835 & 1.649 & 2.075 \\
\hline Elasticity of labour supply by 1pp & $\eta_{L L}$ & 1.792 & 1.726 & 1.482 \\
\hline Labour tax by 1pp & $t_{L}$ & 1.568 & 1.410 & 1.773 \\
\hline
\end{tabular}

Source: Own calculation.

To compare our results with existing literature, an obvious choice is the study by Janda et al. (2010b), who analyse the development of Czech brewing industry and optimal alcohol taxation. Using the methodology of Anderson and Baumberg (2006) and statistical data on Czech alcohol consumption, an analogy of a model developed by Pogue and Sgontz (1989) is used to estimate the optimal tax on alcohol, balancing social costs and benefits connected with beer production and consumption. In order to maximize the welfare of society, alcohol consumers are divided into two groups: abusers and non-abusers, differing in volume and elasticity of alcohol demand.

Janda et al. (2010b) use quite diverse sets of parameters, varying in levels of external abuse costs (with and without intangible costs) and assumptions about the number of abusers attributed to each alcoholic beverage as well as their elasticities of demand. Results of their four models are summarized in Table 9. 
Table 9 | Optimal Tax Comparison - Model by Janda et al. (2010)

\begin{tabular}{|l|c|c|}
\hline & Tax per litre of ethanol (CZK) & Tax per litre of the beverage (CZK) \\
\hline Beer & $85-415$ & $3.58-17.45$ \\
\hline Wine & $56-416$ & $5.67-42.43$ \\
\hline Spirits & $43-284$ & $17.14-113.67$ \\
\hline
\end{tabular}

Source: Janda et al. (2010b) - Socially Optimal Taxation of Alcohol: The Case of Czech Beer

The range of the optimal taxes calculated by Janda et al. (2010b) is generally wider than the one in this paper, which is likely to be the result of quite borderline assumptions in some of their model cases. The fact that all their mean, and especially the lower-bound, estimates are much lower can be attributed to them considering only externality rationales, whereas our study also accounts for other aspects such as the labour, tax-interaction and productivity effects, which go generally in favour of higher tax. This is especially true for spirits. Whereas Janda et al. (2010b) propose that optimal tax on spirits is the lowest of all three beverages (which is in contradiction to existing excise tax rates), our results suggest that spirits should be taxed the most among the three beverages. This difference in results could be attributed to the fact that our model does not rely solely on price elasticity (which is assumed to be the highest for spirits), but also takes into account other effects. The tax interaction effect, for example (which is not a part of the model by Janda et al., 2010b), seems to be relatively strong for spirits. Both our models, however, agree in the general finding that the optimal beer and wine taxes in the Czech Republic seem to be higher than their existing levels.

\section{Conclusions}

Regardless of possible benefits of alcohol production and consumption, it has significant negative external effects. The scale of costs is very broad, including medical expenditures, productivity loss, drunk driving accidents and police and law costs. Alcohol taxes seem to be a suitable means of addressing these externalities. Using a static general-equilibrium model with a representative agent, we found that in order to find the optimal level of beer taxation, which balances social costs and benefits, government should set the tax rates between $4 \mathrm{CZK}$ and $7.8 \mathrm{CZK}$ per 0.51 of beer. Our analysis suggests that under most of the combinations of parameters, taxes on beer in the Czech Republic are lower than their optimal levels. On the other hand, the optimal tax was shown to be slightly below its current level when low values were applied to parameters with a high degree of uncertainty. This implies the need for more empirical research into some of the model parameters. Besides externality correction, these optimal levels are also determined by fiscal considerations as increase in taxation is assumed to immediately change other governmental policies such as labour taxation or medical expenditures. By decomposing the estimated optimal tax into four components, we conclude that the fiscal component 
significantly affects the optimal tax rate as it may be as large as or even greater than the externality-correcting component. Apart from taxes on beer, our analysis also estimates tax on wine of $20.5 \mathrm{CZK} / 1-37.4 \mathrm{CZK} / 1$ and tax on spirits of $65.9 \mathrm{CZK} / 1-142 \mathrm{CZK} / 1$, which shows that optimal tax rates on different alcoholic beverages should vary according to their characteristics.

In the future, this study could be extended in many different ways. As said above, more empirical research into some of the model parameters (e.g., leisure cross-price elasticities) is needed for a more accurate estimation of the optimal tax levels. Similarly to Parry et al. (2009), we could estimate the optimal tax levels decreasing public spending and increasing drunk driving penalties, as alcohol taxes are typically justified as a means of raising government revenues. Intangible costs of alcohol consumption such as pain or psychical harm to families of alcohol abusers were not considered in our analysis - another expansion could therefore include these in our model. Finally, a similar type of analysis might be used to estimate the optimal taxes on other goods with negative external effects such as tobacco and cannabis. 


\section{Appendix}

\section{List of variables}

\begin{tabular}{|c|c|c|}
\hline Variable & Description & Equation \\
\hline$A_{i}$ & Alcohol consumption (i ranges through individual types - beer/wine/spirits) & (1) \\
\hline$c_{D}$ & Expected costs of car repair per drunk driver trip & (3) \\
\hline C & Non-alcoholic goods consumption & (1) \\
\hline$D$ & Number of driving trips under the influence of alcohol by the agent & (1) \\
\hline $\bar{D}$ & Number of driving trips under the influence of alcohol by others & $(2)$ \\
\hline$g^{A}$ & Indirect savings in government medical and resource expenditures & (9) \\
\hline$G^{P}$ & Government spending on public goods & (1) \\
\hline$G^{t}$ & Government tax revenue & (3) \\
\hline$H$ & Health risk function & $(2)$ \\
\hline 1 & Leisure time consumption & $(4)$ \\
\hline$L$ & Labour supply (number of hours worked) & (4) \\
\hline$E^{A}$ & Marginal external costs of alcohol consumption & $(8)$ \\
\hline$E^{D}$ & External costs per drunk driver trip & (6) \\
\hline$K_{D}$ & Lump sum coinsurance paid by the agent as a part of car repair costs & $(3)$ \\
\hline$K_{M}$ & Lump sum coinsurance paid by the agent as a part of medical costs & (3) \\
\hline$m p c$ & Marginal private costs of health risks & $(5)$ \\
\hline$M$ & Agent's costs of medical treatment & $(2)$ \\
\hline $\bar{M}$ & Others' costs of medical treatment & (8) \\
\hline$M E G_{G}{ }^{p}$ & Marginal efficiency gain/loss from spending on public goods & (6) \\
\hline$M E G_{t_{L}}$ & Marginal efficiency gain from cutting labour tax & $(8)$ \\
\hline$P R^{A}$ & Productivity effect of alcohol tax given reduction in alcohol consumption & $(8)$ \\
\hline$P V^{A}$ & Pigouvian tax, equal to marginal external costs of alcohol consumption & $(8)$ \\
\hline$P_{A}$ & Producer price of alcohol & (4) \\
\hline$r$ & Costs for enforcing drunk-driving penalties paid by the government & (3) \\
\hline$R R^{A}$ & Revenue-recycling tax & $(8)$ \\
\hline$s$ & Share of medical costs financed from public budget & (3) \\
\hline$t_{A}$ & Tax on alcohol (in the form of an excise tax) & $(3)$ \\
\hline$t_{D}$ & Expected fine per drunk driver trip & (3) \\
\hline$t_{L}$ & Effective tax on labour & (3) \\
\hline$T_{H}$ & Available time (that could be distributed between work and leisure), as a function of $H$ & (4) \\
\hline$T I^{A}$ & Tax-interaction effect from change in labour supply due to the alcohol price rise & (8) \\
\hline$U$ & Utility function aggregated over all households & $(3)$ \\
\hline$w$ & Wage & (3) \\
\hline$W_{H}$ & Effective labour, as a function of $H$ & (7) \\
\hline$\eta_{A A}$ & Elasticity of alcohol consumption with respect to the price of alcohol & $(6)$ \\
\hline$\eta_{D A}$ & Elasticity of drunk driving with respect to the price of alcohol & (6) \\
\hline$\eta_{A 1}$ & Elasticity of demand for alcohol with respect to leisure & (9) \\
\hline$\eta_{\ddot{u} ;} \eta_{k i}$ & Own-price; cross-price elasticity of demand for individual beverage types & $(9)$ \\
\hline$\eta_{L L}$ & Elasticity of labour supply & (9) \\
\hline$\eta_{L I}$ & Income elasticity of labour supply & (9) \\
\hline$\eta^{c}$ & Compensated elasticity (in general) & $(9)$ \\
\hline$\lambda$ & Marginal utility of income & (5) \\
\hline$\tau_{D}$ & Non-pecuniary penalties (e.g., license suspensions, jail) per drunk driver trip & (1) \\
\hline$u_{D}$ & Variable payment charged by insurance companies as a fraction of medical expenses & (3) \\
\hline$u_{M}$ & Variable payment charged by car insurance companies per drunk driver trip & (3) \\
\hline
\end{tabular}

Source: Own calculation. 
Deriving equation (7):

Using (1) and (4), agents solve the following optimization problem:

$$
\begin{gathered}
V\left(t_{A}, t_{L}, I, G^{P}, \bar{D}\right)=\operatorname{Max} U\left(A, D, C, T(H)-L\left(H, \tau_{D} D, G^{P}\right)+\right. \\
+\lambda\left\{\left(1-t_{L}\right) w+G^{T}-K_{M}-K_{D}-\left(p_{A}+t_{A}\right) A-\left(v_{D}+t_{D}\right) D-v_{M} M-p_{c} C\right\} .
\end{gathered}
$$

From partially differentiating (12):

$$
\frac{\partial V}{\partial t_{A}}=-\lambda A ; \quad \frac{\partial V}{\partial t_{L}}=-\lambda w L ; \quad \frac{\partial V}{\partial G^{P}}=U_{G^{P}} ; \quad \frac{\partial V}{\partial \bar{D}}=-\lambda H_{\bar{D}} m p c ; \quad \frac{\partial V}{\partial \bar{I}}=\lambda .
$$

Totally differentiating (12) with respect to $t_{A}$ using (13) gives:

$$
\frac{1}{\lambda} \frac{\partial V}{\partial t_{A}}=-A-W \frac{d t_{L}}{d t_{A}}+\frac{d I}{d t_{A}}+\frac{U_{G} P}{\lambda} \frac{d G^{P}}{d t_{A}}-H_{\bar{D}} m p c \frac{d D}{d t_{A}} .
$$

Totally differentiating the government budget constraint (14) with respect to $t_{A}$, allowing $t_{L}$, $G^{T}$ and $G^{P}$ to vary, gives:

$$
\frac{d G^{T}}{d t_{A}}-W \frac{d t_{L}}{d t_{A}}=t_{L} \frac{d W}{d t_{A}}+A+t_{A} \frac{d A}{d t_{A}}-s \frac{d M}{d t_{A}}+\left(t_{D}-r\right) \frac{d D}{d t_{A}}-\frac{d G^{P}}{d t_{A}} .
$$

Substituting $K_{M}=\left(1-s-v_{M}\right) M$ and $K_{D}=\left(c_{D}-v_{D}\right) D$ (from the zero profit condition for medical and car insurance companies) into $I=G^{T}-K_{M}-K_{D}$ and totally differentiating with respect to $t_{A}$ gives

$$
{\frac{d I}{d t_{A}}}_{A} \frac{d G^{T}}{d t_{A}}-\left(1-s-v_{M}\right) \frac{d M}{d t_{A}}-\left(c_{D}-v_{D}\right) \frac{d D}{d t_{A}} .
$$

Substituting (16) and (17) in (15) and grouping terms gives:

$$
\begin{gathered}
\frac{1}{\lambda} \frac{\partial V}{\partial t_{A}}=-\left(1-v_{M}\right) \frac{d M}{d t_{A}}-\left(H_{\bar{D}} m p c+c_{D}-v_{D}-t_{D}+r\right) \frac{d D}{d t_{A}}+ \\
+t_{A} \frac{d A}{d t_{A}}+t_{L} \frac{d W}{d t_{A}}+\left(\frac{U_{G}{ }^{P}}{\lambda}-1\right) \frac{d G^{P}}{d t_{A}} .
\end{gathered}
$$

Let us assume that medical services can be expressed as a simple function of alcohol consumption, own drunk driving and drunk driving of others (as these variables drive medical care demand through their impact on health): $M=M(A, D, \bar{D})$.

Differentiating the expression with respect to $t_{A}$ gives:

$$
\frac{d M}{d t_{A}}=M_{A} \frac{d A}{d t_{A}}+M_{D} \frac{d D}{d t_{A}}+M_{\bar{D}} \frac{d \bar{D}}{d t_{A}} .
$$

In addition, we define elasticities as:

$$
\eta_{A A}=\frac{d A}{d t_{A}} \frac{p_{A}+t_{A}}{A} ; \eta_{d A}=\frac{d D}{d t_{A}} \frac{p_{A}+t_{A}}{D} .
$$

Substituting (18) and (19) in (17) gives, after some manipulation, equation (6). 
Deriving equation (9):

From totally differentiating the government budget constraint (3) with respect to $t_{A}$, allowing $t_{L}$ to vary with $G^{T}$ and $G^{P}$ fixed using (7), gives:

$$
=-\frac{A+t_{A} \frac{d A}{d t_{A}}+\left(t_{D}-r\right) \frac{d D}{d t_{A}}-s \frac{d M}{d t_{A}}+t_{L}\left\{w \frac{\partial L}{\partial t_{A}}+\frac{\partial W}{\partial H} \frac{d H}{d t_{A}}\right\}}{w\left\{L+t_{L} \frac{\partial L}{\partial t_{L}}\right\}} .
$$

From (20) and the first equation in (9):

$$
t_{L} w \frac{\partial L}{\partial t_{L}} \frac{d t_{L}}{d t_{A}}=M E G_{t_{L}}\left\{A+t_{A} \frac{d A}{d t_{A}}+\left(t_{d}-r\right) \frac{d D}{d t_{A}}-s \frac{d M}{d t_{A}}+t_{L}\left(w \frac{\partial L}{\partial t_{A}}+\frac{\partial W}{\partial H} \frac{d H}{d t_{A}}\right)\right\} .
$$

Substituting (7) and (21) into (6), with $d G^{T} / d t_{A}=d G^{P} / d t_{A}=0$, gives:

$$
\begin{aligned}
& \left(E^{A}-t^{A}\right)\left(\frac{-d A}{d t_{A}}\right)+M E G_{t_{L}}\left\{A+t_{A} \frac{d A}{d t_{A}}+\left(t_{D}-r\right) \frac{d D}{d t_{A}}\right\}+ \\
& +\left(1+M E G_{t_{L}}\right) t_{L} \frac{w \partial L}{\partial t_{A}}+\left(1+M E G_{t_{L}}\right) t_{L} \frac{\partial W}{\partial H} \frac{d H}{d t_{A}} .
\end{aligned}
$$

From the Slutsky equation:

$$
\frac{\partial L}{\partial t_{A}}=\frac{\partial L^{C}}{\partial t_{A}}-\frac{\partial L}{\partial I} A ; \quad \frac{\partial L}{\partial t_{L}}=\frac{-\partial L^{C}}{\partial \tilde{w}} w-\frac{\partial L}{\partial I} w L
$$

where the superscript $c$ denotes a compensated coefficient and $\partial L / \partial I$ is the income effect on labour supply.

From the Slutsky symmetry property:

$$
\frac{\partial L^{C}}{\partial t_{A}}=-\frac{\partial A^{C}}{\partial \tilde{w}},
$$

where $\tilde{w}=\left(1-t_{L}\right) w$ denotes the net tax wage.

In addition, we define elasticities:

$$
\eta_{L L}=\frac{\partial L^{C}}{\partial \tilde{w}} \frac{\tilde{w}}{L} ; \eta_{A l}^{C}=\frac{\partial A^{C}}{\partial \tilde{w}} \frac{\tilde{w}}{A} ; \eta_{L L}=\frac{\partial L}{\partial I} \frac{\tilde{w} I}{L} .
$$

Equating (22) to zero and substituting (23) and (24) gives (8), where $g^{A}$ is defined in (9) and elasticities in (25). 


\section{References}

Anderson, P., Baumberg, B. (2006). Alcohol in Europe: A Public Health Perspective. UK: Technical report, Institute of Alcohol Studies.

Cupak, A., Pokrivcak, J., Rizov, M. (2015). Food Demand and Consumption Patterns in the New EU Member States: the Case of Slovakia. Ekonomicky casopis, 63(4), 339-358.

Cupak, A., Pokrivcak, J., Rizov, M. (2016). Demand for Food Away from Home in Slovakia. Czech Journal of Economics and Finance, 66(4), 354-369.

Council Directive 92/83/EEC of 19 October 1992 on the Harmonization of the Structures of Excise Duties on Alcohol and Alcoholic Beverages.

Czech Statistical Office (2012). Statistical Yearbook of the Czech Republic - 2012. Available at: https: //www.czso.cz/csu/czso/statistical-yearbook-of-the- czech-republic-2012-qxfyvy48ev

Dybczak, K., Toth, P., Vonka, D. (2014). Effects of Price Shocks on Consumer Demand: Estimating the QUAIDS Demand System on Czech Household Budget Survey Data. Czech Journal of Economics and Finance, 64(6), 476-500.

Eurostat (2013). Available at: http://ec.europa.eu/eurostat/data/database

Fogarty, J. (2010). The Demand for Beer, Wine and Spirits: A Survey of the Literature. Journal of Economic Surveys, 24(3), 428-478, https://doi.org/10.1111/j.1467-6419.2009.00591.x

Gallet, C. A. (2007). The Demand for Alcohol: a Meta-analysis of Elasticities. The Australian Journal of Agricultural and Resource Economics, 51(2), 121-135, https://doi. org/10.1111/j.1467-8489.2007.00365.x

Hait, P. (2012). Smoking - Impact on the State Budget and its Fair Taxation. IES, Charles University in Prague. Prague Working Paper.

Hogarty, T. F., Elzinga, K. G. (1972). The Demand for Beer. The Review of Economics and Statistics, 54(2), 195-198, https://doi.org/10.2307/1926282

Horska, E., Bercik, J., Krasnodebski, A. et al. (2016). Innovative Approaches to Examining Consumer Preferences when Choosing Wines. Agricultural Economics, 62(3), 124-133, https://doi.org/10.17221/290/2015-agricecon

Institute for Fiscal Studies (Great Britain) (2009). Dimensions of Tax Design: the Mirrlees Review. Oxford: Oxford University Press.

Janda, K., Mikolášek, J., Netuka, M. (2010). Complete Almost Ideal Demand System Approach to Czech Alcohol Demand. Agricultural Economics, 56(9), 421-434, https://doi. org/10.17221/117/2009-agricecon

Janda, K., Mikolášek, J., Netuka, M. (2010b). Socially Optimal Taxation of Alcohol: The Case of Czech Beer. Presentation at Agricultural and Applied Economics Association (AAEA) 2010 Annual Meeting, July 25-27, 2010, Denver, Colorado.

Janda, K., Mikolášek, J. (2011). Success in Economic Transformation of the Czech beer Industry and its Social Costs and Benefits. Transformations in Business and Economics, 10(3), 117-137.

Janský, P. (2014). Consumer Demand System Estimation and Value Added Tax Reforms in the Czech Republic. Czech Journal of Economics and Finance, 64(3), 246-273.

Janský, P. (2016). Impact of the Changes in Excise Duties on Households in the Czech Republic. Agricultural Economics, 62(2), 51-61, https://doi.org/10.17221/31/2015-agricecon

Kenkel, D. S. (1996). New Estimates of the Optimal Tax on Alcohol. Economic Inquiry, 34(2), 296-319, https://doi.org/10.1111/j.1465-7295.1996.tb01379.x 
Kucerova, R. (2014). Factors of the Attractiveness of Slovak Wine Market and their Influence on the Czech Wine Export to Slovakia. Agricultural Economics, 62(9), 430-439, https://doi. org/10.17221/130/2013-agricecon

Levitt, S. D., Porter, J. (2001). How Dangerous Are Drinking Drivers? Journal of Political Economy, 109(6), 1198-1237, https://doi.org/10.1086/323281

Lyon, A. B., Schwab, R. M. (1995). Consumption Taxes in a Life-Cycle Framework: Are Sin Taxes Regressive? The Review of Economics and Statistics, 77(3), 389-406, https://doi. org/10.2307/2109902

Manning, W. G. (1989). The Taxes of Sin: Do Smokers and Drinkers Pay their Way? Journal of the American Medical Association, 261(11), 1604-1609, https://doi.org/10.1001/ jama.1989.03420110080028

Meng, Y., Brennan, A., Purshouse, R. et al. (2014). Estimation of Own and Cross Price Elasticities of Alcohol Demand in the UK-A Pseudo-Panel Approach Using the Living Costs and Food Survey 2001-2009. Journal of Health Economics, 34(C), 96-103, https://doi. org/10.1016/j.jhealeco.2013.12.006

Nelson, J. P. (2014). Estimating the Price Elasticity of Beer: Meta-Analysis of Data with Heterogeneity, Dependence, and Publication Bias. Journal of Health Economics, 33(C), 180-187, https://doi.org/10.1016/j.jhealeco.2013.11.009

Parry, I. W. H., West, S. E., Laxminarayan, R. (2009). Fiscal and Externality Rationales for Alcohol Policies. The B.E. Journal of Economic Analysis \& Policy, 9(1), 1935-1682, https://doi. org/10.2202/1935-1682.2133

Pogue, T. F., Sgontz, L. G. (1989). Taxing to Control Social Costs: The Case of Alcohol. American Economic Review, 79(1), 235-243.

Saar, I. (2011). Optimal Alcohol Taxation: Simulation Results for Estonia. Baltic Journal of Economics, 11(1), 65-90, https://doi.org/10.1080/1406099x.2011.10840491

Saffer, H., Chaloupka, F. (1994). Alcohol Tax Equalization and Social Costs. Eastern Economic Journal, 20(1), 33-43.

Sandmo, A. (1975). Optimal Taxation in the Presence of Externalities. Swedish Journal of Economics, 77(1), 86-98, https://doi.org/10.2307/3439329

Sloan, F., Eldred, L. (2015). Do Preferences of Drinker-Drivers Differ? International Journal of Health Economics and Management, 15(2), 241-268, https://doi.org/10.1007/ s10754-015-9169-x

Slováčková, T., Birčiaková, N., Stávková, J. (2016). Forecasting Alcohol Consumption in the Czech Republic. Procedia - Social and Behavioral Sciences, 220, 472-480, https://doi. org/10.1016/j.sbspro.2016.05.522

Srivastava, P., McLaren, K. R., Wohlgenant, M., Zhao, X. (2014). Econometric Modelling of Price Response by Alcohol Types to Inform Alcohol Tax Policies. Monash University, Department of Econometrics and Business Statistics. Working Paper No. 05/14.

Syrovátka, P., Chládková, H., Žufan, P. (2014). Wine Consumption in the Czech Republic and the Prices of Alcohol. Agricultural Economics, 60(2), 89-98, https://doi.

org/10.17221/114/2013-agricecon

Široký, J. (2013). Daně v Evropské Unii. 6th edition. Praha: Linde. ISBN 978-80-7201-925-0.

Tomšík, P., Prokeš, M. (2011). New Strategic Alliances of Wine Producers in the Czech Republic. Agricultural Economics, 57(12), 573-579, https://doi.org/10.17221/183/2011-agricecon

Zákon o spotřebních daních. 353/2003 Sb. 